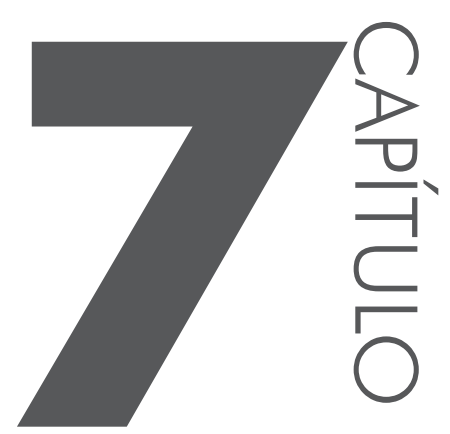

\title{
Narrativa nos jogos: uma oportunidade para autoria coletiva na escola
}

Arthur Protasio Jorge de Oliveira, Mestre, Pontifícia Universidade Católica do Rio de Janeiro (PUC-Rio)/ Fundação Getulio Vargas (FGV)

Cynthia Macedo Dias, Doutoranda, Pontifícia Universidade Católica do Rio de Janeiro (PUC-Rio)/ Núcleo de Tecnologias Educacionais em Saúde da Escola Politécnica de Saúde Joaquim Venâncio da Fundação Oswaldo Cruz (Nuted-Fiocruz)

\section{INTRODUÇÃO}

A presença dos jogos na educação já não é nova e apresenta-se por meio de diversas estratégias, como a aplicação de jogos ditos "educativos", a utilização de jogos comerciais com a finalidade de disparar debates sobre determinados conteúdos, a leitura crítica de jogos, a produção de jogos (ou a modificação de jogos existentes) com alunos e a própria "gamificação", como aplicação de elementos de jogos em situações 
outras (MATTAR, 2010). Cada estratégia utiliza-se de diferentes concepções do que são jogos, de qual o seu lugar na escola e seu potencial nesse contexto, bem como de quais dos seus elementos são mais relevantes em cada momento.

Neste artigo, vamos dar ênfase a uma visão dos jogos como produtos culturais e objetos de design, que engendram processos interativos e podem confirmar ou questionar sentidos e valores que permeiam a cultura onde se encontram (FARBIARZ; OLIVEIRA, 2014). A partir desse olhar, pretendemos investigar a relevância da narrativa como elemento integrante de um jogo (eletrônico, digital ou analógico), como ela se reflete nas práticas de uso, análise e construção de jogos e como pode potencializá-las na escola. Ao destacar a função ou papel da narrativa e as distinções que se manifestam em razão dessa abordagem, colocamos nosso foco no aspecto narrativo dos jogos e na sua construção, que não desconsidera, mas, pelo contrário, se alimenta da estrutura das regras e da estética dos jogos.

\section{A NARRATIVA COMO ATIVIDADE HUMANA}

Ricoeur (1994) estabelece que as narrativas são formas de criar representações da vida humana e apaziguar nossos anseios como indivíduos impotentes diante da passagem do tempo. Fazendo alusão à mimese, que Aristóteles reconhece sempre como uma representação produtora, Ricoeur traça uma categorização por etapas. Cada uma delas, na sua visão, constrói diferentes tipos de representações e a formação de todos eles completaria um círculo, gerando uma espiral sem fim.

O autor explica que há sempre um momento anterior à criação de uma narrativa: a mimese 1 seria a representação desse momento pré-narrativo ou do mundo prático que antecede a narração. Mas, para que este seja representado, é necessário haver algum tipo de pré-compreensão: a aceitação de um mundo já dotado de sentidos e significado, mas que é imbuído de discordância.

A partir da pré-compreensão dessa representação já existente (a mimese 1), ocorre a mimese 2, que é a tessitura da intriga propriamente dita. Nesse momento, é elaborada uma trama para imprimir sentido e unidade dramática aos fatos. Ao transformá-los em eventos, cria-se uma nova realidade que visa promover uma releitura sobre a anterior. Embora a intriga tenha tido grande relevância na Grécia Antiga, esse modelo ainda se aplica nos dias atuais a qualquer criação narrativa, que sempre se apropria de uma realidade que serve como base para a criação de novos eventos.

No entanto, uma vez que a intriga é tecida pelo narrador, ela chega ao leitor. A leitura é realizada e ocorre a recepção da narrativa. Essa leitura inevitavelmente afeta a intriga (da mimese 2) com base na realidade pré-narrativa (mimese 1) e garante um novo sentido aos eventos narrados. Afinal, não só todos os seres humanos são inerentemente diferentes como o leitor não participou do processo de tessitura da intriga e, dessa forma, sua base de conhecimento e perspectiva diverge 
da do narrador. A mimese 3 simboliza a etapa final de um processo em espiral contínuo de representações humanas, quando ocorre a "refiguração" da intriga, uma nova configuração de sentido dada a partir da interpretação do leitor.

Esse entendimento não é exclusivo de Ricoeur (1994). Goulemot (1996) afirma que

qualquer leitura é uma leitura comparativa, contato do livro com outros livros. Assim como existe dialogismo e intertextualidade, no sentido que Bakthin dá ao termo, há dialogismo e intertextualidade da prática da própria leitura. Entretanto, não há nada aqui que seja mensurável. Estamos no campo das hipóteses e do provável. Ler será, portanto, fazer emergir a biblioteca viva, quer dizer, a memória de leituras anteriores e de dados culturais. (Goulemot Apud Chartier, 1996, p. 113).

Para Goulemot, essa "biblioteca” é a memória de leituras anteriores e dados culturais, e essa definição se assemelha muito à realidade pré-narrativa da mimese 1 de Ricoeur. Assim, qualquer leitura realizada sempre apresentará uma "refiguração" de sentidos diferente da anterior, pois a todo o momento o leitor incorpora mais elementos à sua biblioteca a partir de constantes leituras.

Esse entendimento é crucial para fechar o ciclo do processo em espiral, pois após a mimese 3 uma nova mimese 1 se forma. Afinal, se a interpretação da intriga (mimese 3) já foi consolidada, é chegada a hora de encará-la como uma nova realidade pré-narrativa (mimese 1 ) que servirá de base para a construção de intrigas posteriores. Ao final, gera-se um novo início para que o atual leitor possa, futuramente, tecer uma nova narrativa mediante a intriga (mimese 2), para explicar os eventos que lhe causem angústia diante da temporalidade. Logo, concretiza-se um processo ilustrativo de por que o humano narra.

Gottschall (2012) faz uma interessante complementação ao processo de mimeses descrito por Ricoeur (1994) ao notar que narrativas são como simuladores de voo. Assim como o simulador, muitas vezes as histórias permitem que indivíduos sejam preparados e treinados para grandes desafios da vida. A ficção é capaz de gerar problemas paralelos aos que são vividos e projetar o indivíduo em uma realidade alternativa, em que ele é capaz de testar diversos limites e verificar seus resultados sem ser diretamente afetado no mundo real.

O autor continua, afirmando que a ficção é uma poderosa e antiga tecnologia de realidade virtual que simula os dilemas da vida humana. O ato de ouvir, ler ou assistir uma história é algo arrebatador, capaz de promover tamanha empatia com seus personagens ao ponto de o leitor poder sentir os eventos como se estivessem realmente acontecendo com ele.

Para além de uma preparação para o "futuro", consideramos que a narrativa atua também como espaço de troca de perspectivas e um deslocamento político, como forma de conhecer outras realidades. Evidentemente, como essas, existem 
outras abordagens teóricas e conceituais em relação à narrativa, mas vamos nos ater às apresentadas até aqui para, em seguida, desdobrá-las em relação aos jogos.

\section{A NARRATIVA APLICADA AOS JOGOS}

Diversos autores já se detiveram na definição do que seriam os jogos, utilizando diferentes ênfases em cada abordagem; dentre eles, o próprio artigo que nos antecede neste livro dedica-se a esta tarefa, a partir das discussões estabelecidas no grupo de trabalho (GT) jogos na educação no evento SILID/SIMAR ${ }^{3}$, que integramos. Assim, contribuindo para a compilação, com base nos estudos de Huizinga (1971), Parlett (1999), Caillois (1962 apud SALEN; ZIMMERMAN, 2003), Juul e Crawford (2002 apud SALEN; ZIMMERMAN, 2003), Salen e Zimmerman (2003), acreditam que um jogo pode ser melhor definido a partir de elementos norteadores, identificados em variadas definições de jogos. Para eles, jogos são (1) uma atividade, processo ou evento que (2) possui regras que limitam os jogadores; (3) objetivos; (4) estabelecem conflitos ou competições; (5) envolvem tomada de decisões; (6) são artificiais; (7) e voluntários.

Frasca (1999) menciona o método estruturalista de classificação das atividades lúdicas desenvolvido por Roger Callois (1962 apud SALEN; ZIMMERMAN,, 2003) e a definição de jogo de Huizinga (1971), porém apresenta uma preocupação com a ênfase na sua estrutura ludológica, ou seja, as regras e elementos que compõem o cerne da experiência interativa. Para Frasca (1999), os jogos são detentores de elementos narrativos, e por isso suas regras podem ser abertas o suficiente para permitir que o jogador determine a forma como quer participar da experiência. Apesar de não se tornarem autores da estrutura, a liberdade dada confere a eles a autoria das ações realizadas, diferente de uma narrativa tradicional onde a intriga é fechada e imutável. Dessa forma, ele acredita que a narrativa complemente o jogo na medida em que, ao apresentar elementos críveis e identificáveis, será possível estimular o pensamento crítico por parte do jogador e caracterizar o jogo como uma mídia ideal para discutir e explorar questões pessoais e sociais.

Ao passo que os conceitos de narrativa se aplicam à estrutura dos jogos, eles o fazem sob condições diferenciadas. Conforme Salen e Zimmerman (2003), ao jogar, o jogador interage com e dentro de um universo representacional, um espaço de possibilidades repleto de dimensões narrativas. Segundo os autores, quando comparados

3 Tanto neste quanto nos outros artigos que compõem o presente livro, quando mencionarmos um determinado Grupo de Trabalho (GT), os resumos das comunicações dos autores poderão ser acessados em: <http://www.designnaleitura.net.br/silid-simar/caderno_resumos/ Caderno\%20 de $\% 20$ Resumos $\% 20$ V\%20SILID \% >. Neste caso específico, o artigo apresentado no GT intitulado "Construção de jogo como dispositivo para a aprendizagem colaborativa: algumas estratégias” serve como exemplo de experiência de construção colaborativa de jogo e pode ser acessado em: <http://www.proceedings.blucher.com.br/article-details/construo-de-jogo-como-dispositivo-para-a-aprendizagem-colaborativa-algumas-estratgias-22590>. 
à estrutura clássica de uma história, muitos jogos também contêm um início, desenvolvimento e conclusão. A diferença está no fato de que este paralelismo não necessariamente se dá em relação a personagens e um enredo, mas em relação à estrutura do jogo como compêndio de regras, e os eventos são desencadeados a partir do jogar.

Os jogos e as representações presentes neles não existem de maneira isolada do restante da cultura. Pelo contrário, há uma série de elementos que derivam de outras mídias e, por isso, exibem elementos que frequentemente são familiares para os jogadores. Afinal, se adotarmos os estudos de Ricoeur (1994) e Goulemot (1996) como base, entenderemos que o ser humano lê situações e histórias a todo momento ao longo de sua vida, o que resulta em um contínuo acréscimo da biblioteca pessoal e criação de novas mimeses.

Precisamente por isso é que Salen e Zimmerman (2003) afirmam que a criação de narrativas de jogos significa brincar e jogar com os campos da cultura, bem como convenções da cultura popular, literatura, entretenimento, arte e mídias em geral. Nenhuma representação é neutra e, em um jogo, quanto mais relevantes elas forem, maior a chance de estimularem uma experiência convidativa e engajante.

Entretanto, segundo Bissell (2010), embora muitos jogos eletrônicos sejam comparados com filmes, suas formas de contar histórias são significativamente diferentes. O cinema é capaz de escolher exatamente o que mostrar em tela e, assim, comprime suas histórias;já os jogos não costumam impor esta determinação sobre seus jogadores e ganhando valor ao demonstrarem a importância de observar uma constelação em vez de uma única estrela.

Por isso, muitas convenções tradicionalmente utilizadas para contar histórias acabam por não se sustentar quando aplicadas à estrutura dos jogos. Bissell (2010) reforça que os padrões operados são significativamente diferentes e frequentemente carecem das mecânicas de participação que são tão importantes para os jogos. Ele reforça que jogos, filmes e romances são economias distintas e separadas que lidam com a moeda corrente histórias.

Grip (2012) acrescenta que jogos podem ter o mesmo impacto que outras mídias, mas podem se adaptar ao jogador, oferecendo conteúdo que se conforme às suas escolhas. Nesse sentido, jogos são capazes de estimular uma profunda reflexão no jogador quanto ao seu ser e, por isso, distinguem-se de outras mídias que contam histórias. Gomes (2009) também traz luz a essa discussão ao identificar este dilema narrativo vivido pelos jogos: de um lado, a tentativa de dar ao interator toda liberdade que o meio pode lhe propiciar e, de outro, a necessidade de circunscrever suas atitudes a um mínimo de estrutura dramática na experiência do game. (Gomes, 2009, p.67)

Jogos convidam indivíduos para seus mundos virtuais, nos quais permitem que cada jogador molde seu ser a partir de suas decisões e sinta tristeza, amor ou admiração. Isto, contudo, só é possível com a valorização da presença do jogador dentro do universo do sistema e, em muitos aspectos, aproxima-se do conceito de participação significativa. 
Salen e Zimmerman (2003) apresentam uma distinção que ajuda a pensar essa dinâmica de dupla autoria e de um dilema narrativo nos jogos, bem como ajudam a verificar o potencial para a participação significativa neles. Estas seriam as duas formas de compreender como o sistema de um jogo é capaz de produzir narrativa: a narrativa embutida e a narrativa emergente.

A narrativa embutida é a história inserida no sistema do jogo que confere sentido e contexto às regras, de autoria do criador do jogo. Ações simplesmente inerentes às mecânicas de interação poderiam soar abstratas e destituídas de propósito. Assim, a narrativa embutida visa conferir uma participação significativa ao jogador por meio de elementos do enredo, como premissa da história, personagens e sequência de eventos que conferem uma unidade dramática às interações e jornada do jogador.

Salen e Zimmerman (2003) afirmam, inclusive, que a narrativa embutida tende a se parecer com os elementos típicos das experiências narrativas que mídias tradicionais, como livros e filmes, costumam oferecer - como um roteiro. Um determinado diálogo entre personagens, um texto específico a ser lido, uma música, um confronto ou essencialmente qualquer elemento que seja imutável e pré-estabelecido, como também as representações visuais e as mecânicas de interação, contribuem diretamente para a experiência narrativa nos jogos.

Contudo, como destacado anteriormente, há outra possibilidade narrativa de extrema importância para a mídia do jogo eletrônico: a narrativa emergente, a história que é criada a partir da experiência interativa do jogador. A sua base também é planejada pelo produtor do jogo, mas é impossível prever todos os seus desdobramentos. Isso se dá em função de os eventos criados serem uma consequência orgânica da liberdade exercida pelo jogador diante das mecânicas de jogo e sua produção de sentidos como usuário.

A narrativa emergente depende não só da ação do jogador, mas também do que está ocorrendo no sistema naquele exato momento, pois as circunstâncias/contexto no sistema não são necessariamente as mesmas. A ênfase da narrativa emergente está na forma como o jogador interage com o sistema do jogo e cria a sua própria e única sequência de fatos. O resultado de suas ações e a sequência de eventos criada - planejados ou não pelo criador da obra - geram uma narrativa da qual o jogador se sente autor.

Salen e Zimmerman (2003) acreditam que as duas modalidades de narrativa, além de serem inerentes a toda experiência de jogo, quando bem trabalhadas, atingem uma forma de simbiose. Quando coexistindo em equilíbrio, as narrativas embutida e emergente promovem uma relação mutuamente vantajosa de comunicação e colaboração, que permite a criação de experiências narrativas únicas. Ao oferecer uma participação significativa, por sua vez, pode-se vir a promover uma simbiose entre o jogo e o jogador.

Dessa forma, fica claro que a narrativa nos jogos definitivamente não se resume a pedaços de uma história que existem para atrair o jogador a progredir, mas uma atividade contínua que promove engajamento com as mecânicas de 
interação por meio de escolhas. Elementos como a incerteza diante de situações futuras e a chance de se expressar por meio de decisões morais, por exemplo, são situações que encorajam o envolvimento do jogador.

Por fim, ao discutir a articulação de estruturas de mecânicas de participação e narrativa nos jogos, vale mencionar Krawczyk e Novak (2006). As autoras demonstram que, além de poderem ter diversos gêneros, uos jogos podem se assumir numa variedade de estruturas narrativas.

A maioria dos jogos eletrônicos é linear. Boa parte dos estágios, personagens e enredos em jogos são apresentados de forma que haja um início, meio e fim claramente estabelecidos. Há alguma liberdade que diz respeito especificamente às mecânicas de interação, para remover os obstáculos que se apresentam adiante - inimigos ou eventos dramáticos -, mas frequentemente trata-se de um trilho bem definido, pois qualquer desvio não previsto é impedido pelas limitações do sistema ou recepcionado com uma tela de "game over".

Jogos que conferem ao jogador a possibilidade de escolher quais destes caminhos ele deseja percorrer são considerados jogos ramificados. Naturalmente, em retrospecto, trata-se de um jogo linear - afinal, apenas um caminho, ainda que composto por diversos caminhos menores, foi percorrido - mas a lógica é que o jogador teve a oportunidade de optar. Assim, a história e seus personagens podem assumir novas facetas. É possível seguir adiante ainda que figuras importantes morram ou que o jogador fracasse em determinadas missões, o que é computado como um "sucesso alternativo", já que um fracasso tradicional resultaria no fim do jogo. Assim, cria-se uma estrutura muito parecida com um fluxograma que prevê todas as trajetórias possíveis diante de decisões previstas pelo desenvolvedor do sistema.

Há, também, um terceiro tipo de história que não é completamente diferente dos dois primeiros, mas apresenta uma espécie de "evolução", a história aberta, enredo que permite ao jogador habitar o mundo ficcional de maneira livre, sem ser pressionado para prosseguir. É comum que existam motivos que incentivem o jogador a seguir em frente, uma trama com objetivos a cumprir ou mesmo uma linearidade na história, mas o sistema não irá penalizar o jogador por explorar o universo no seu próprio tempo e determinar seus próprios objetivos durante toda duração do jogo ou durante um momento específico da experiência ${ }^{4}$.

\section{NARRATIVAS NOS JOGOS E APRENDIZAGEM}

A partir dos autores apresentados, podemos dizer que os jogos (especialmente os digitais, mas não apenas estes), assim como os filmes e demais produtos au-

4 Em inglês, este modelo de história e estrutura interativa é identificado pelo termo sandbox, que é o equivalente a uma caixa de areia onde crianças geralmente brincam. A ênfase nessa proposta está em permitir que o jogador crie sua própria história a partir de suas decisões. 
diovisuais, são mídias que participam de um ecossistema cultural, com a diferença de que os jogos convidam à participação e à autoria conjunta dos jogadores em níveis mais aprofundados das narrativas.

Algumas abordagens que associam jogos à educação alinham-se a essa forma de vê-los como produtos culturais, portadores e potencializadores de narrativas. $\mathrm{Na}$ área da educomunicação ou educação midiática, os jogos são vistos como meios a serem conhecidos e explorados, compondo uma "ludoliteracia", cujo domínio estaria para além dos jogos estritamente definidos, incluindo processos "gamificados" e o que os autores chamam de uma tendência geral da sociedade digital para processos "lúdicos” (JUÁREZ; MARTÍNEZ; SÁNCHES-NAVARRO, 2014). A importância dessa literacia estaria na possibilidade de ampliar o controle de crianças, jovens e adultos em relação ao consumo desses meios, e sua concretização dependeria de considerar o "lúdico digital" como "um meio distinto dos demais, que gera significados, prazeres e requer competências analíticas e criativas próprias" (Ibid., p. 223).

Para Zagal (2010, p. 24), essa literacia seria composta de três habilidades: 1) habilidade de jogar; 2) habilidade de entender os significados em relação com os jogos; e 3) habilidade de criar jogos. Albuquerque (2014) defende um "letramento eletrolúdico", com a finalidade de que os estudantes não só conheçam os mecanismos da indústria e os sentidos presentes nos jogos, mas também reflitam sobre sua relação com eles, conhecendo diferentes modos de jogar e suas potenciais consequências, favorecendo a decisão consciente sobre suas atitudes em relação ao jogar.

É evidente, como Salen e Zimmerman (2013) apontam, que quanto mais ricas forem as narrativas emergentes e quanto mais estas promoverem um equilíbrio com a potencial construção de narrativas emergentes por parte dos jogadores, mais significativa torna-se essa participação e, consequentemente, maior a sensação de autoria compartilhada por parte dos jogadores. Por isso, para aproveitar um dos potenciais para os jogos na escola, torna-se relevante a busca e a experimentação de jogos que possibilitem diferentes experiências narrativas: lineares, ramificadas ou abertas. A partir daí, possibilidades de trabalho seriam provocar a reflexão sobre as experiências vividas, sobre a abertura de possibilidades, pensar a criação de novos caminhos para narrativas fechadas; e a discussão da opção por determinados caminhos e os sentidos contidos em cada caminho ou na multiplicidade deles.

É importante ressaltar também que, independentemente de haver uma intenção "educativa", qualquer experiência de jogo pode se configurar em uma ressignificação do sujeito e sua posição como coautor do jogo. A experimentação da narrativa dos jogos (mimeses 2 construídas pelos produtores dos jogos a partir da mimese 1 dos elementos do mundo) pode propiciar a construção de uma mimese 3, fruto da experiência de jogo. Essa mimese pode estar representada em um debate sobre a experiência, uma produção textual ou imagética, um depoimento ou mesmo nas trocas e diálogos durante a sessão de jogo. 
Em um nível ainda mais aprofundado, a construção de jogos por alunos pode ser entendida como um exercício do momento da mimese 2 , de tessitura de uma intriga: a partir da experiência do mundo e/ou de novos conhecimentos adquiridos, ou mesmo da experiência de jogar um jogo, tece-se uma nova narrativa interativa coletiva, que articula a discordância, o desafio, a dificuldade, a inquietação, o desequilíbrio. Essa autoria coletiva pode construir regras, objetivos para o jogador, enredo, elementos narrativos, visuais e de regras, provocando a necessidade de dar sentidos coletivos aos elementos da realidade acessados, questioná-los e de buscar novos conhecimentos.

Entretanto, na qualidade de autores de jogos, professores e alunos devem, ainda, buscar aproveitar o potencial dessa mídia ao pensar em uma participação significativa dos futuros jogadores. Dessa forma, refletir sobre as decisões adotadas, procurando articular a narrativa embutida no enredo e nas regras com a promoção da narrativa emergente. Que tipos de caminhos as regras do jogo permitem? Quais os sentidos que esses caminhos e que as próprias regras apontam? As regras e o que elas pedem dos jogadores encontram ressonância nos discursos presentes no enredo, na narrativa embutida construída? Elas servem para suscitar reflexões sobre questões da realidade? Quais as possibilidades de escolha do jogador para a construção de sua própria narrativa emergente? Essas possibilidades de escolha acrescentam aos sentidos já presentes na narrativa embutida?

\section{CONSIDERAÇÕES FINAIS}

A meta principal deste artigo foi entender a narrativa conforme as limitações e peculiaridades da mídia do jogo e apontar possibilidades de como ela se reflete nas práticas de uso, análise e construção de jogos, potencializando-as na escola. Por isso, diante da compreensão estabelecida para a narrativa em um plano mais geral, foi crucial identificar a multiplicidade de visões de autores referentes ao segmento dos jogos eletrônicos.

Em síntese, os termos utilizados por Salen e Zimmerman tornaram-se nossas referências para identificar nos jogos as duas modalidades narrativas que apontam os eventos que foram criados e fornecidos pelo desenvolvedor na condição de criador (narrativa embutida) e os eventos criados pelas ações do jogador durante o momento de interação (narrativa emergente). Ao mesmo tempo, os conceitos de mimese de Ricoeur e as visões de Goulemot sobre a leitura e de Gottschall sobre a narrativa como "simulador de voo" colocam-se como parâmetros para pensar as narrativas de jogos na escola.

Conclui-se que os jogos operam narrativas de forma diferente de muitas mídias e a sua inerente interação altera padrões substanciais. Alerta-se aqui para o fato de que não levar em conta a participação do jogador (ou subestimá-la) pode levar à criação de uma experiência muito próxima de outras mídias e muito aquém do potencial das 
mídias digitais interativas. Pensar no planejamento da narrativa de um jogo desvinculada de seu sistema é desconsiderar as particularidades da mídia. Afinal, se há o processo de design de jogos, logo, há também o design de sua narrativa.

Em suma, a intenção deste artigo é, aprofundando um dos tópicos discutidos no GT Jogos na educação do evento SILID/SIMAR, que o conhecimento em relação à narrativa aplicada aos jogos seja valorizado na formação docente para sua consequente utilização nas escolas, em qualquer situação de uso ou produção de jogos (analógicos ou digitais) ou narrativas interativas. O presente artigo não se trata de um manual de regras ou práticas, mas da exploração de conceitos que norteiem uma linha de pensamento. Afinal, acredita-se que a eficaz utilização da narrativa em um jogo é capaz não só de valorizá-lo como um projeto de design, mas especialmente de aperfeiçoar a sua relação com o jogador, potencializando a construção de narrativas e destacando a aprendizagem embutida no processo.

Se um escritor escreve para seu leitor, um criador de um jogo não deve subestimar ou se esquecer de seu jogador. $\mathrm{O}$ jogador também é o autor, autor de uma obra criativa, construída a partir dos fundamentos oferecidos pelo produtor. $\mathrm{O}$ resultado é uma tela preparada pelo desenvolvedor, mas pintada pelo jogador, de forma a demonstrar a individualidade de cada experiência. Por mais similares e lineares que as experiências possam ser, a mínima participação de cada jogador é o suficiente para caracterizar o jogo como um canal de comunicação de ideias e consolidar sua narrativa como uma criação única de cada pessoa.

Enxergar essas particularidades é poder ver alunos e professores não apenas como coautores ao jogar, mas como potenciais construtores de narrativas expressas nas narrativas embutidas nos jogos e nas possibilidades previstas de narrativas emergentes.

\section{REFERÊNCIAS}

ALBUQUERQUE, R. M. Letramento eletrolúdico como conscientização: bases teóricas para educar o jogar. Currículo sem Fronteiras, v. 14, n. 2, p. 57-74, maio/ ago 2014.

BISSEL, T. Extra lives: why video games matter. Nova York: Pantheon Books, 2010. Livro eletrônico.

FRASCA, G. Ludology meets narratology: similitude and differences between (vídeo)games and narrative. Ludology.org, 1999. Disponível em: <http://www. ludology.org/articles/ludology.htm>. Acesso em: 1 jul. 2013.

GOMES, R. Shenmue e o dilema narrativo. In: SANTAELLA, Lucia; FEITOZA, Mirna. Mapa do Jogo: a diversidade cultural dos games. São Paulo: Cengage Learning, 2009.

GOULEMOT, J. M. Da leitura como produção de sentidos. In: CHARTIER, Ro- 
ger (org.). Práticas da leitura. Tradução Cristiane Nascimento. São Paulo: Estação Liberdade, 1996. p. 107-116.

GOTTSCHALL, J. The storytelling animal: how stories make us human. Boston: Houghton Mifflin Harcourt, 2012. Livro eletrônico.

GRIP, T. The self, presence and storytelling. In the games of madness, 20 ago. 2012. Disponível em: <http://frictionalgames.blogspot.com.br/2012/08/the-self-presence-and-storytelling.html> Acesso em: 22 nov. 2013.

HUIZINGA, J. Homo Ludens. São Paulo: EDUSP, 1971.

KRAWCZYK, M.; NOVAK, J. Game development essentials: game story \& chatacter development. Clifton Park: Thomson Delmar Learning. 2006.

MATTAR, J. Games em educação: como os nativos digitais aprendem. São Paulo: Pearson Prentice Hall, 2010.

OLIVEIRA, A. P. J.; FARBIARZ, J. L. Jogando histórias : refletindo sobre a narrativa dos jogos eletrônicos. 2014. Dissertação (Mestrado)-Pontifícia Universidade Católica do Rio de Janeiro, Departamento de Artes e Design, 2014 Disponível em : <http://www.dbd.pucrio.br/pergamum/biblioteca/php/mostrateses.php?open=1\&arqtese=1213338_2014_ Indice.html>. Acesso em : 1 mai. 2016.

PARLETT, D. The Oxford History of Board Games. Oxford: Oxford University Press, 1999.

RICOEUR, P. Tempo e narrativa - Tomo I. tradução de Constança Marcondes César. Campinas: Papirus, 1994.

SALEN, K. ZIMMERMAN, E. Rules of play: game design fundamentals. Cambridge: MIT Press, 2003. Livro eletrônico.

SÁNCHEZ-NAVARRO, J.; JUÁREZ, D. A.; MARTÍNEZ, Silvia S. El juego digital e internet como ecosistema lúdico. Jerarquía de medios para ele entretenimiento y alfabetizaciones emergentes. In: Agentes e Vozes: um panorama da mídia-educação no Brasil, Portugal e Espanha.Yearbook 2014. Ilana Eleá (Org.). Portuguese/Spanish edition. Taberg, Sweden: The International Clearinghouse on Children, Youth and Media, 2014.

ZAGAL, J. P. (2010). Ludoliteracy: Defining, Understanding, And Supporting Games Education. ETC Press, paper 4. Disponível em http://press.etc.cmu.edu/ files/Ludoliteracy-JoseZagal-web.pdf. Acesso em 11/09/2015. 